ORIGINAL ARTICLE

\title{
Core-peripheral temperature gradient as a diagnostic test in dyspnoea
}

\section{S F J Clarke, R J Parris, K Reynard}

Emerg Med J 2005;22:633-635. doi: 10.1136/emj.2004.017624

See end of article for authors' affiliations

....................

Correspondence to: Dr S Clarke, Locum Consultant in Emergency Medicine, South Manchester University Hospital, Southmoor Road, Wythenshawe,

Manchester, M23 9LT, UK; sficlarke@doctors.org.uk

Accepted 9 August 2004
Objectives: To evaluate whether the core-peripheral temperature gradient could be used to distinguish between cardiac and respiratory causes of dyspnoea.

Methods: In total, 50 patients were enrolled in the study, based on the following inclusion criteria: (a) a primary presenting complaint of dyspnoea; (b) age $>40$ years; (c) respiratory rate $>20 \mathrm{breaths} / \mathrm{min}$; (d) hypoxia. The tympanic temperature and the temperature of the nasal tip were recorded, and the patient's discharge data and chest $x$ ray results checked. Where there was discordance, arbitration was carried out by another researcher.

Results: Four patients were excluded, hence the final study sample was 46 patients. There was a statistically significant difference between the mean temperature gradients of the two study populations $(p<0.001)$. A gradient of $>8^{\circ} \mathrm{C}$ was able to rule in a cardiovascular cause ( $92 \%$ specificity) whereas one of $<5^{\circ} \mathrm{C}$ could rule it out ( $100 \%$ sensitivity ).

Conclusion: The test is safe, non-invasive and inexpensive. Although there were some limitations to the study, the test can still be commended as a useful adjunct to the emergency assessment of the acutely breathless patient.
A patient presenting to an emergency department (ED) with dyspnoea is a common problem that requires rapid diagnosis and treatment, but may present a diagnostic dilemma. Dyspnoea may be the manifestation of a wide range of pathological conditions, most commonly lung or heart disease, that share similar risk factors and that often coexist. It may be difficult to obtain a history from a severely breathless patient, thus useful information such as other symptoms, previous episodes, and drug therapy may be unobtainable or missed. The breathless patient may have clinical features that do not easily differentiate the key causes.

The severity of illness is often such that treatment cannot be delayed pending the results of chest radiography or other investigations. This may result in treatment with any combination of bronchodilators, steroids, nitrates, diuretics, or antibiotics prior to a definitive diagnosis being made. This polypharmacy has the potential for adverse effects and adds to the cost of patient care.

Since the 1960s the measurement of changes in skin temperature and, more latterly, the core-peripheral temperature gradient, has been advocated as an indirect, noninvasive method of monitoring the treatment of shock; ${ }^{1-10}$ it has been used in the postoperative care of cardiothoracic surgical patients ${ }^{11-14}$ and in neonatal intensive care medicine, ${ }^{15}$ and it has been advocated as an indication of haemodynamic dysfunction during cardiac exercise testing. ${ }^{16}$

Reduced peripheral perfusion is an early feature of symptomatic cardiac disease, as opposed to respiratory failure, in which it develops late in the pathological process. The aim of this study was to evaluate the ability of the coreperipheral temperature gradient in helping to distinguish between cardiac and respiratory causes of dyspnoea.

\section{PATIENTS AND METHODS}

The ED of South Manchester University Hospital sees approximately 65000 new patients yearly, with shortness of breath being the primary presenting condition in approximately $5 \%$ of adult patients. The hospital receives tertiary referrals for both cardiology and respiratory medicine.

Ethics committee approval was granted for the study. Patients fulfilling the following inclusion criteria were invited to participate in the study: (a) a primary presenting complaint of dyspnoea; (b) age $>40$ years; $(c)$ respiratory rate $>20$ breaths/min; (d) hypoxia, as measured by pulse oximetry $\left(\mathrm{SpO}_{2}<90 \%\right.$ with the patient breathing room air, or $<96 \%$ on supplemental oxygen). No other factors influenced the recruitment of patients.

The attending doctor recruited eligible patients who were given both written and verbal information regarding the study. An infrared thermometer (Genius First Temp; Tyco Health Care, Hampshire, UK) that could measure both tympanic and surface temperature was used to measure the tympanic membrane temperature and the nose tip temperature, the latter by holding the instrument just above the skin in "scan" mode. These measurements were made only once, as would happen in routine clinical practice, and were made early in the assessment of the patient as an extension of the routine measurement of observations and therefore before a clinical diagnosis was made. The actual temperature gradients were calculated at a later date and therefore did not influence diagnosis or management.

Each patient's tympanic temperature and the highest reading from their nasal tip was recorded on a standardised form, along with their demographic details and specific inclusion criteria.

The "gold standard" diagnosis was obtained using both clinical and radiological criteria. Firstly, the medical records were searched for the discharge diagnosis; secondly, the initial chest $x$ ray for each patient was reviewed by one of two consultant radiologists who reported the evidence for heart or pulmonary pathology on each film to provide a radiological diagnosis. If the discharge and $x$ ray diagnoses concurred, then this was taken as the "gold standard"; if they disagreed, then the notes and $x$ rays of this and any available previous admissions were scrutinised by one of the authors (KR) who arbitrated. All of these assessments were carried out by 
personnel blinded to the core-peripheral temperature gradient. In patients who subsequently died, the postmortem diagnosis was sought.

A list of temperature gradients for each diagnosis (cardiac or pulmonary) was constructed, and the mean, median, and range for each list was calculated; Student's $t$ test was performed to ascertain the significance of the difference between the two study populations. The ability of the temperature gradient to diagnose cardiovascular disease was assessed by calculating the specificities, sensitivities, and likelihood ratios of a range of different temperature gradients by constructing a series of $4 \times 4$ tables as previously described; ${ }^{17}$ a receiver operator characteristic (ROC) curve was derived from these results.

\section{RESULTS}

In total, 50 patients were entered in the study. These patients were recruited as a convenience sample, although patients were enrolled during both day and night. Four patients were excluded from the analysis: two did not fulfil the inclusion criteria and two were lost to follow up (no record could be found of one patient, while the other was transferred to another hospital and their chest $x$ ray could not be located), thus the final study sample was 46 patients.

Overall, 21 patients (46\%) had a diagnosis of cardiovascular disease (including two with angiographically confirmed pulmonary embolism), the remaining 26 (54\%) having respiratory pathology. Table 1 contains the demographic characteristics and summary details of the temperature gradients of the two groups. There was a statistically significant difference between the mean temperature gradients of the two study populations $(p<0.001)$. The sensitivities, specificities, and likelihood ratios for a range of values of temperature gradient are shown in table 2 and the ROC curve in fig 1.

\section{DISCUSSION}

Measuring the skin temperature provides an indirect, noninvasive assessment of the state of the peripheral circulation. This is influenced by both cardiac output and the tone of the arteriolar vessels, which are in turn affected by numerous interrelated factors such as blood volume, myocardial contractility, sympathetic nervous system stimulation, circulating vasoactive substances, and local homeostatic mechanisms.

Much of the published evidence on the temperature gradient has focussed on its clinical applications in shock. Studies have indicated that changes in peripheral temperature have prognostic ${ }^{256812-14}$ and diagnostic ${ }^{41-14}$ value in hypovolaemic and cardiogenic shock, and can be used as a non-invasive guide to adequacy of fluid ${ }^{1378}$ and even inotropic therapy. ${ }^{3}$ This study demonstrates that the patients with cardiovascular causes for their breathlessness have significantly different test results $(p<0.001)$ from those with respiratory causes (table 2).

Table 1 Characteristics of the study subpopulations

\begin{tabular}{lll}
\hline Characteristic & Cardiovascular & Respiratory \\
\hline No. of patients & 21 & 25 \\
Male:female ratio & $7: 14$ & $10: 15$ \\
Age, mean (range) & $74(46$ to 90$)$ & $69(45$ to 93$)$ \\
TG & & \\
Mean (range) & $8.67(5.1$ to 12.1$)$ & $4.88(2.2$ to 11.3$)$ \\
SD (95\% Cl) & $2.16(7.75$ to 9.59$)$ & $2.20(4.02$ to 5.74$)$ \\
\hline
\end{tabular}

TG, temperature gradient; SD, standard deviation; $\mathrm{Cl}$, confidence interval.

\begin{tabular}{|c|c|c|c|c|}
\hline $\begin{array}{l}\text { Core } \\
\text { peripheral } \\
\text { TG ('C) }\end{array}$ & Sensitivity & Specificity & $\mathbf{L R}+$ & LR - \\
\hline 3 & 1.00 & 0.12 & 1.14 & 0 \\
\hline 4 & 1.00 & 0.40 & 1.67 & 0 \\
\hline 5 & 1.00 & 0.64 & 2.78 & 0 \\
\hline 6 & 0.86 & 0.76 & 3.57 & 0.18 \\
\hline 7 & 0.76 & 0.88 & 6.35 & 0.27 \\
\hline 8 & 0.62 & 0.92 & 7.74 & 0.41 \\
\hline 9 & 0.43 & 0.92 & 5.36 & 0.62 \\
\hline 10 & 0.38 & 0.96 & 9.52 & 0.65 \\
\hline 11 & 0.19 & 0.96 & 4.76 & 0.84 \\
\hline 12 & 0.10 & 1.00 & $\infty$ & 0.90 \\
\hline
\end{tabular}

At $\Delta \mathrm{T} \geqslant 8^{\circ} \mathrm{C}$ to diagnose a cardiovascular cause for breathlessness, the specificity was $92 \%$ (positive likelihood ratio 7.74). Using this level as a criterion for cardiac causes of breathlessness allows targeted treatment to be commenced while the results of further tests, including chest radiographs, are awaited. In this study, $33 \%$ of patients could be considered the "rule in" group-that is, a cardiac cause could be diagnosed. Sensitivity was maintained at $100 \%$ with $\Delta \mathrm{T}$ $\leqslant 5^{\circ} \mathrm{C}$ (negative likelihood ratio 0 ). Cardiac causes of breathlessness were ruled out by $\Delta \mathrm{T} \leqslant 5^{\circ} \mathrm{C}$; this is likely to be useful clinically. In this study, $39 \%$ of patients fell into this group.

The test was applied to unselected patients attending the ED. Using a $\Delta \mathrm{T} \leqslant 5^{\circ} \mathrm{C}$ cut off to rule out a cardiac cause for the dyspnoea and a $\Delta \mathrm{T} \geqslant 8^{\circ} \mathrm{C}$ cut off to rule in, almost three quarters of these patients could have their emergency treatment limited to appropriate agents while a chest $x$ ray was performed and other information obtained.

A potential weakness of the study is the position of the sites of temperature measurement, which were chosen for their ease of use. All of the clinicians who enrolled patients to the study were trained in the use of the thermometer, which should have minimised variations in tympanic readings. However, temperature of the nasal tip could be influenced by

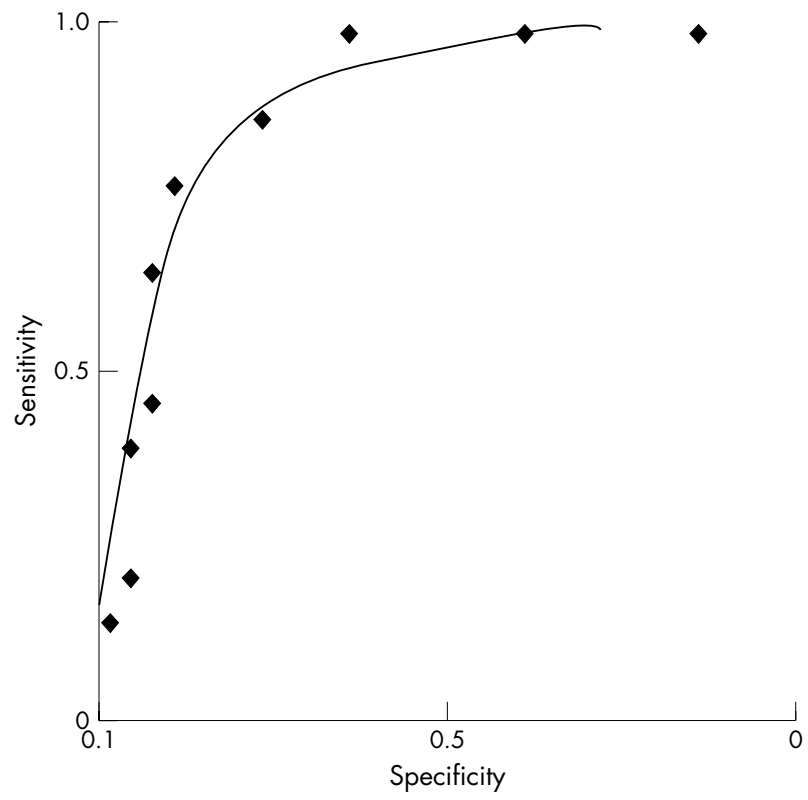

Figure 1 ROC curve. 


\section{What is already known on this topic}

- The core-peripheral temperature gradient has been used as a non-invasive assessment of haemodynamic status.

- Clinical examination does not always readily distinguish between cardiac and respiratory causes of dyspnoea, and therefore appropriate treatment can be delayed.

\section{What this paper adds}

- Measurement of the difference between tympanic and nasal tip temperatures can be used to distinguish between cardiac and respiratory causes of dyspnoea.

- This study proposes a novel use for the measurement of the core-peripheral temperature gradient: a gradient of $>8^{\circ} \mathrm{C}$ can be used to rule in a cardiovascular cause (92\% specificity) whereas one of $<5^{\circ} \mathrm{C}$ can rule it out (100\% sensitivity).

the oxygen flow given to the patient, with higher flows having a greater cooling effect than lower flows (which may be given to patients with chronic obstructive airway disease). Although at the time of the study, the local ambulance service that brought all of the patients to the department had a policy of giving high flow oxygen therapy ( $15 \mathrm{l} / \mathrm{min}$ via a reservoir mask) to all breathless patients, this could be a potential confounding factor to future use. Further assessment is required in this patient group, and further research is planned to attempt to validate these results using the great toe as an alternative site for measurement of peripheral temperature.

The test is safe, non-invasive and inexpensive. We did not assess the effect on outcomes of applying this test result to directing patient treatment but the test can still be commended as a useful adjunct to the emergency assessment of the acutely breathless patient.

\section{Authors' affiliations}

S F J Clarke, R J Parris, South Manchester University Hospital, Southmoor Road, Wythenshawe, Manchester, UK

K Reynard, St James's University Hospital, Beckett Street, Leeds, UK

Competing interests: Tyco Healthcare provided a tympanic membrane thermometer and disposables for the duration of the study. No other funding was received.

We thank A Horrocks and R Sawyer for reviewing the chest radiographs of the patients in the study.

\section{REFERENCES}

1 Ibsen B. Treatment of shock with vasodilators measuring skin temperature on the big toe. Dis Chest 1967;52:425.

2 Joly HR, Weil MH. Temperature of the great toe as an indication of the severity of shock. Circulation 1969;39:131-8.

3 Aynsley-Green A, Pickering D. Use of central and peripheral temperature measurements in the care of the critically ill child. Arch Dis Child 1974;49:447-81

4 Brock L, Skinner JM, Manders JT. Observations on peripheral and central temperatures with particular reference to the occurrence of vasoconstriction. Br J Surg 1975;62:589-95.

5 Ruiz CE, Weil HM, Carlson RW. Treatment of circulatory shock with dopamine. JAMA 1979;242:165-8.

6 Henning RJ, Weiner F, Valdes S, et al. Measurement of toe temperature for assessing severity of acute circulatory failure. Surg Gynecol Obstet 1979;149:1-7.

7 Kholoussy AM, Sufian S, Pavlides C, et al. Central peripheral temperature gradient. Its value and limitations in the management of critically ill surgical patients. Am J Surg 1980;140:609-12.

8 Cowan BN. Relative prognostic value of lactate and haemodynamic measurements in early shock. Anaesthesia 1984;39:750.

9 Vincent JL. Toe temperature versus transcutaneous oxygen tension monitoring during acute circulatory failure. Intensive Care Med 1988;14:64.

10 Hinds CJ, Watson D. Intensive care: a concise textbook, 2nd ed. London: WB Saunders, 1996.

11 Ross BA, Brock L, Aynsley-Green A. Observations on central and peripheral temperature in the understanding and management of shock. $\mathrm{Br} J$ Surg 1969:56:877-82.

12 Matthews HR, Meade JB, Evans CC. Peripheral vasoconstriction after openheart surgery. Thorax 1974;29:338-42.

13 Matthews HR, Meade JB, Evans CC. Significance of prolonged peripheral vasoconstriction after open-heart surgery. Thorax 1974;29:343-8.

14 Kirklin JK. Intracardiac surgery in infants under age 3 months: predictors of post-operative in-hospital cardiac deaths. Am J Cardiol 1981;48:507.

15 Lambert HJ, Baylis PH, Coulthard MG. Central-peripheral temperature difference, blood pressure, and arginine vasopressin in preterm neonates undergoing volume expansion. Arch Dis Child (Fetal Neonatal Ed) 1998;78:F43-45.

16 Griffin MJ, O'Sullivan JJ, Scott A, et al. Core and peripheral temperature response to exercise in patients with impaired left ventricular function. $\mathrm{Br}$ Heart J 1993;69:388-90.

17 Sackett DL, Haynes RB, Guyatt GH, et al. Clinical epidemiology: a basic science for clinical medicine, 2nd ed. Boston, Toronto, London: Little, Brown and Co, 1991 . 